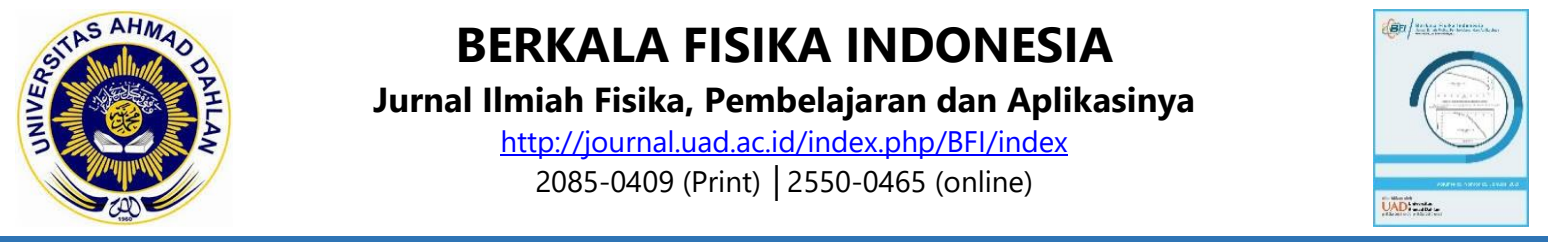

\title{
Perancangan lembar kerja peserta didik berbasis STEM pada materi elastisitas dan hukum Hooke
}

\author{
Sherin Widianawati ${ }^{1 *}$, Dwi Sulisworo ${ }^{2}$ \\ ${ }^{1}$ Pendidikan Fisika, Fakultas Keguruan dan Ilmu Pendidikan, Universitas Ahmad Dahlan, Indonesia \\ 2 Magister Pendidikan Fisika, Fakultas Keguruan dan Ilmu Pendidikan, Universitas Ahmad Dahlan, Indonesia \\ Email: sherin9339@gmail.com * \\ * Penulis korespondensi
}

\begin{tabular}{l}
\hline Informasi artikel \\
\hline Sejarah artikel: \\
Dikirim \\
Revisi \\
Diterima \\
\hline Kata kunci: \\
Bahan Ajar \\
STEM \\
LKPD
\end{tabular}

\section{Keywords: \\ Teaching Materials \\ STEM}

Student Worksheets

\begin{abstract}
ABSTRAK
Pendekatan Science, Technology, Engineering, and Mathematics (STEM) dalam LKPD sangat cocok untuk membekali keterampilan $4 \mathrm{C}$ kepada siswa. Penelitian ini bertujuan untuk mengembangkan Lembar Kerja Peserta Didik (LKPD) berbasis STEM pada materi elastisitas dan hukum Hooke. Jenis penelitian ini adalah Research and Development. Metode pengembangan LKPD mengadopsi 7 dari 10 tahapan pengembangan model Borg \& Gall. Produk diujicobakan kepada peserta didik kelas XI MIPA SMA/MA. Kelayakan LKPD ditinjau dari sisi materi dan media. Teknik analisis data dilakukan dengan mengubah data kualitatif menjadi data kuantitatif. Hasil uji kelayakan menunjukkan LKPD layak dari sisi materi dan sisi media sehingga dapat digunakan dalam pembelajaran fisika.

This is an open access article under the CC-BY-SA license

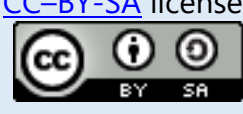

ABSTRACT
STEM-based student worksheet design on elasticity material and Hooke's law. The
Science, Technology, Engineering, and Mathematics (STEM) approach in LKPD is very
suitable for equipping 4C skills. This study aims to develop STEM-based Student Worksheets
(LKPD) on elasticity and Hooke's law. This type of research is the Research and Development
Method. The development of LKPD adopts 7 of the 10 stages of development which is the
Borg \& Gall model. The product was tried out for class XI MIPA SMA / MA students. The
feasibility of LKPD is viewed from the material and media side. The data analysis technique
is done by converting qualitative data into quantitative data. The results of the feasibility
test show that LKPD is feasible in terms of the material and the media side so that it can be
used in learning physics.
\end{abstract}

How to Cite:

Widianawati, S., \& Sulisworo, D. (2020). Perancangan lembar kerja peserta didik berbasis STEM pada materi elastisitas dan hukum Hooke. Berkala Fisika Indonesia: Jurnal Ilmiah Fisika, Pembelajaran dan Aplikasinya, 11(2), 68-75. 


\section{Pendahuluan}

Sains dan teknologi semakin berkembang pada abad kedua puluh satu di seluruh dunia (Redhana, 2019). Fisika merupakan salah satu disiplin ilmu yang memberikan kontribusi bagi kemajuan ilmu pengetahuan dan teknologi dalam perkembangan masyarakat dunia karena merupakan aspek sains yang paling mendasar, yang berhubungan dengan tingkah laku dan penataan benda (Giancoli, 2015). Saat siswa bergabung dengan dunia kerja, mereka harus memiliki keahlian $4 C$ untuk berhasil secara internasional. Berpikir kritis, kemampuan berkomunikasi, kemampuan berkolaborasi, dan kreativitas adalah keterampilan yang dibutuhkan di abad kedua puluh satu (Astuti, Aziz, Sumarti, \& Bharati, 2019; Erdoğan, 2019; Maloy, Verock, Edwards, \& Woolf, 2016; Yu \& Wan Mohammad, 2019). Metodologi integratif digunakan dalam upaya meningkatkan kemampuan 4C. Kurikulum STEM (Science, Technology, Engineering, and Mathematics) adalah cara terbaik untuk melatih siswa bekerja abad ke-21 (Zubaidah, 2019).

Pembelajaran STEM dapat membekali siswa memecahkan permasalahan, menyimpulkan apa yang telah dipelajari sebelumnya serta mengaplikasikannya pada situasi yang berbeda (Lou, Chou, Shih, \& Chung, 2017; Roberts \& Cantu, 2012). Perbedaan pembelajaran STEM dengan model pembelajaran sains lainnya ada pada pola Engineering Design Process (EDP) yang menekankan pada proses mendesain sebuah karya atau mesin dan lingkungan belajar terpadu yang menunjukkan bagaimana metode ilmiah dapat diterapkan dalam kehidupan sehari-hari. Hal ini mengajarkan cara berpikir kritis peserta didik dan berfokus pada aplikasi pemecahan masalah dunia nyata.

Berdasarkan hasil wawancara dengan guru fisika di Madrasah Mu'allimaat Muhammadiyah Yogyakarta, beberapa siswa merasa kesulitan dengan mata pelajaran tersebut, terutama saat mengerjakan soal dan mudah bosan dengan pelajaran fisika. Proses pembelajaran masih berpusat kepada guru. Selain itu, dalam proses pembelajarannya guru sudah mengarah pada pembelajaran STEM, akan tetapi belum maksimal dalam pelaksanaannya dan guru belum menggunakan bahan ajar berbasis STEM. Kekhawatiran ini dapat diselesaikan dengan memberi siswa panduan yang mudah dipahami yang diberikan dengan ramah. Lembar Kerja Peserta Didik adalah contoh alat pendidikan yang penting untuk keberhasilan program belajar-mengajar (Kaymakcı, 2012).

Puri (2019) melakukan kajian tentang pengembangan LKPD Berbasis STEM pada pokok bahasan usaha dan energy di SMA Muhammadiyah 7 Yogyakarta. Kajian ini mengdopsi model pengembangan Borg \& Gall untuk menghasilkan LKPD berbasis STEM. Berdasarkan pendapat ahli materi, ahli media, guru, kolega, dan mahasiswa, rata-rata skor produk ini adalah $83,80 \%$, termasuk dalam kelompok "Sangat Layak".

Irfana dan Yulianti (2019) melakukan penelitian pengembangan LKPD berbasis sains, teknologi, teknik, dan matematika untuk meningkatkan kemampuan berpikir kreatif siswa. Analisis ini bertujuan untuk mengetahui karakteristik LKPD berbasis STEM, mengevaluasi kelayakan, dan mengetahui 
peningkatan kemampuan berpikir kreatif siswa. Kelayakan LKPD dinilai dalam tiga tingkatan: isi, penyajian, dan bahasa, yang kesemuanya menerima peringkat 85,21\% dalam kategori "Sangat Sesuai". Sedangkan hasil uji keterbacaan sebesar 89,66\% menunjukkan bahwa LKPD ini mudah dipahami. Upaya peningkatan berpikir kreatif menggunakan LKPD berbasis STEM ini mampu mengembangkan aspek kelancaran, keluwesan, elaborasi dan keaslian dengan nilai pretest dan posttest mengalami peningkatan dengan kriteria sedang.

Perbedaan dari penelitian yang akan dilakukan dengan penelitian sebelumnya terletak pada materi yang digunakan, model pengembangan yang digunakan, dan pola pembelajaran yang digunakan. LKPD yang akan disusun memiliki kelebihan pada kata pengantar yang lebih religius untuk meningkatkan keimanan peserta didik, LKPD menggunakan pola pembelajaran EDP (Engineering Design Process), LKPD dapat digunakan sebagai pembelajaran mandiri serta alat dan bahan yang digunakan mudah didapatkan. Oleh karena itu, tujuan dari penelitian ini adalah mengembangkan LKPD Berbasis Science, Technology, Engineering, and Mathematics (STEM) pada Pokok Bahasan Elastisitas dan Hukum Hooke.

\section{Metode}

Penelitian ini menggunakan model pengembangan (Sugiyono, 2015). Dalam penelitian ini, peneliti hanya memilih 7 dari 10 pengembangan dikarenakan keterbatasan waktu dalam penelitian dan disesuaikan dengan kebutuhan. Langkah pengembangan yang digunakan dalam penelitian ditunjukkan pada Gambar 1.

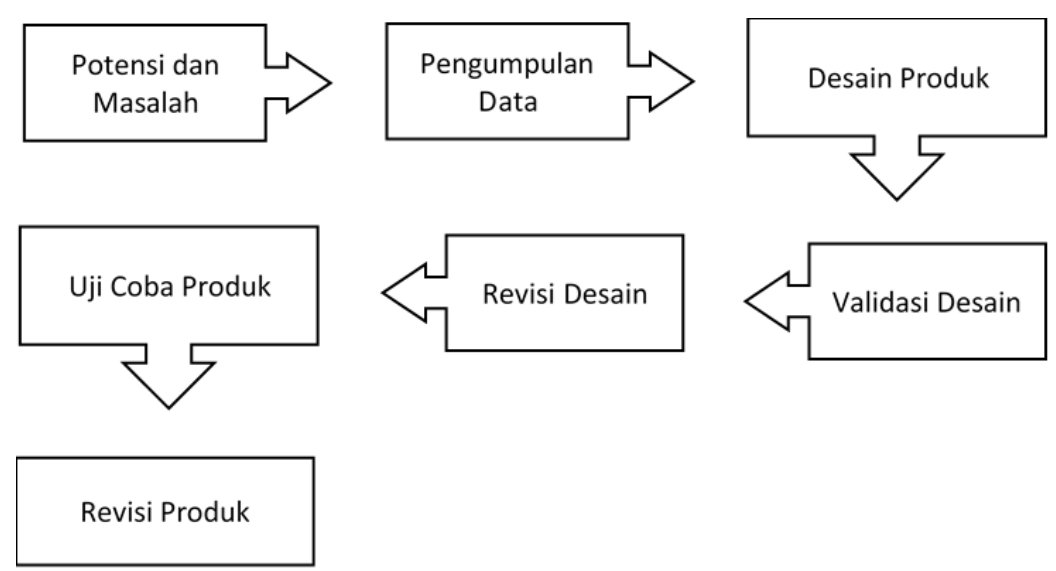

Gambar 1. Prosedur pengembangan

Untuk mengetahui potensi dan masalah yang ada di Madrasah Mu'allimaat Muhammadiyah Yogyakarta, peneliti melakukan wawancara dengan guru fisika dari sekolah tersebut. Potensi yang dimiliki sekolah ini adalah memiliki tenaga pengajar yang mumpuni, fasilitas sekolah yang tergolong lengkap, dan guru sudah menggunakan media dalam proses pembelajaran. Sedangkan masalah yang terdapat di sekolah ini adalah masih ada beberapa peserta didik yang mengalami kesulitan dalam memahami materi fisika dan kesulitan mengerjakan soal, kurangnya antusiasme peserta didik saat 
belajar fisika dan merasa cepat bosan saat belajar fisika, proses pembelajaran masih berpusat kepada guru dan guru belum menggunakan bahan ajar berbasis Science, Technology, Engineering, and Mathematics (STEM).

Pengumpulan data dilakukan untuk mendapatkan data terkait bahan ajar berupa LKPD berbasis STEM yang akan dikembangkan. Maka peneliti melakukan wawancara dengan guru fisika di sekolah tersebut. Melakukan pengumpulan bahan untuk menyusun LKPD di antaranya materi elastisitas dan hukum Hooke, ilustrasi/gambar yang akan digunakan, soal latihan, Rencana Pelaksanaan Pembelajaran (RPP), dan standar isi.

Desain produk Lembar Kerja Peserta Didik (LKPD) berbasis STEM pada pokok bahasan Elastisitas dan Hukum Hooke yang dikembangkan memuat judul/cover, halaman judul, kata pengantar, daftar isi, petunjuk penggunaan LKPD, sintaks pola EDP, standar isi, peta konsep, materi, contoh soal, latihan soal, kegiatan eksperimen sederhana, soal evaluasi, daftar pustaka, biodata penulis, dan kunci jawaban. Desain cover LKPD ditunjukkan pada Gambar 2.

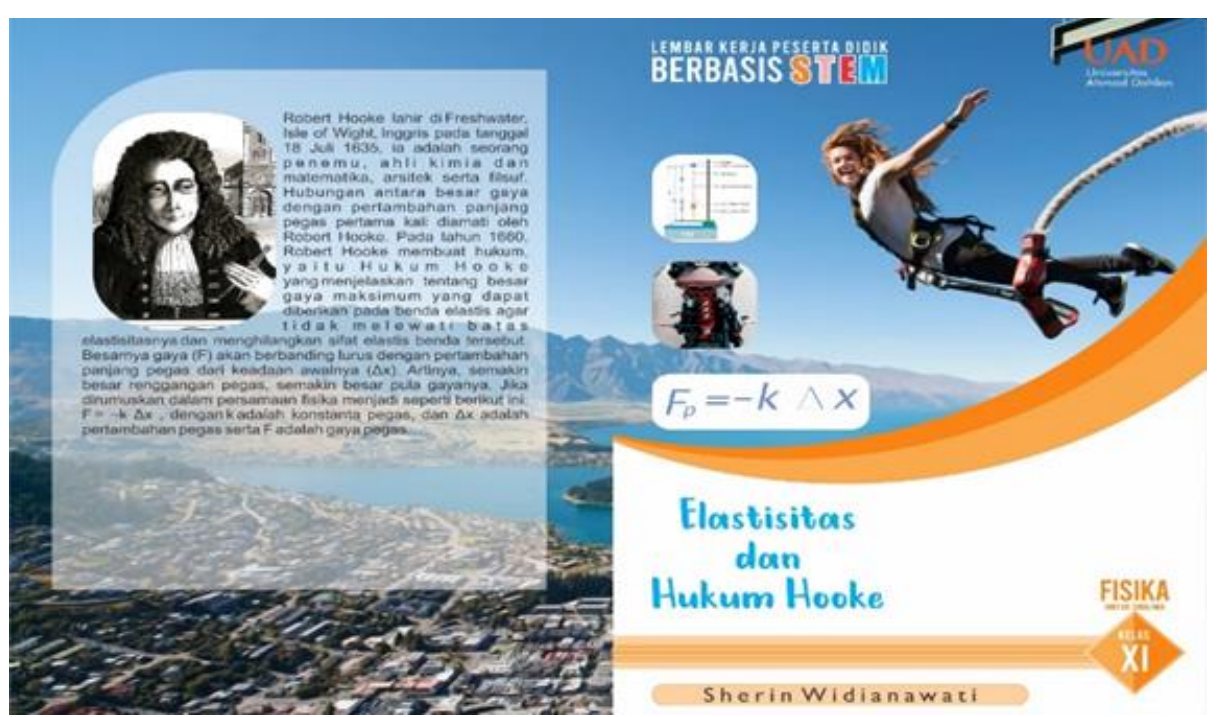

Gambar 2. Desain cover LKPD yang dikembangkan

Validasi desain dilakukan untuk mengetahui tingkat kelayakan produk LKPD berbasis STEM yang telah dikembangkan. Validasi dilakukan oleh ahli materi, ahli media, guru dan teman sejawat. Dalam proses validasi para validator memberikan penilaian dan komentar/saran untuk perbaikan produk. Revisi desain dilakukan berdasarkan saran atau data kualitatif yang diberikan oleh validator untuk perbaikan tahap satu LKPD berbasis STEM agar menjadi lebih baik dan layak diujicobakan kepada responden.

Uji coba produk untuk mengetahui respon dari responden terhadap produk yang dikembangkan. Subjek uji coba produk ini adalah 3 orang peserta didik dari SMAN 8 Yogyakarta kelas XI MIPA, hal ini dilakukan karena uji coba produk tidak dapat dilakukan di MA Mu'allimaat Muhammadiyah Yogyakarta akibat adanya pandemi Covid-19. Kuesioner digunakan untuk mengumpulkan data tentang tanggapan siswa. 
Revisi produk ini merupakan perbaikan tahap kedua yang dilakukan berdasarkan saran atau data kualitatif dari respon peserta didik terhadap LKPD berbasis STEM yang dikembangkan agar menjadi lebih baik.

Instrumen pengumpulan data terdiri dari angket validasi untuk penilaian dari validator dan angket respon peserta didik untuk responden. Terdapat dua jenis data yang diperoleh yaitu data kuantitatif berasal dari penilaian skala Likert dengan skor 1-5 dan data kualitatif berasal dari komentar atau saran yang disampaikan. Teknik analisis data berbentuk persentase dilakukan untuk mengetahui tingkat kelayakan produk yang dikembangkan. Hasil validasi dilakukan oleh ahli materi, ahli media, guru, teman sejawat, dan respon peserta didik. Skor yang diperoleh diolah menggunakan persamaan (1).

$$
P=\frac{S}{N} \times 100 \%
$$

di mana $P$ adalah Tingkat kelayakan (\%), $S$ adalah Jumlah skor total yang diperoleh, dan $N$ adalah Jumlah skor total maksimal ideal. Setelah nilai persentase diperoleh, kemudian dikelompokkan dalam kategori. Produk yang dikembangkan dinyatakan berhasil apabila minimal mencapai persentase pada interval $41 \%$ - 60\%, kriteria Cukup Layak.

\section{Hasil dan Pembahasan}

Penelitian ini berhasil mengembangkan LKPD berbasis STEM pada pokok bahasan elastisitas dan hukum Hooke. Isi dari LKPD ini ditunjukkan pada Gambar 3, Gambar 4 dan Gambar 5. Hasil validasi ahli materi mencakup 4 aspek penilaian yaitu aspek kelayakan isi, penyajian, bahasa dan STEM. Hasil penilaian dari dua ahli materi mendapatkan skor rata-rata sebesar 125 poin dari skor maksimum 150 poin dengan persentase 83,3\% termasuk dalam kategori "Sangat Layak".

Hasil validasi ahli media mencakup 2 aspek penilaian yaitu aspek kelayakan kegrafikaan dan penyajian media. Hasil penilaian dari dua ahli media mendapatkan skor rata-rata sebesar 90,5 poin dari skor maksimum 100 poin dengan persentase 90,5\% termasuk dalam kategori "Sangat Layak".

Hasil validasi guru fisika dan teman sejawat mencakup aspek materi yaitu kelayakan isi, penyajian, bahasa dan STEM dan aspek media yaitu kelayakan kegrafikaan dan penyajian media. Hasil penilaian dari guru fisika mendapatkan skor 215 poin dari skor maksimum 250 poin dengan persentase $86,0 \%$ termasuk dalam kategori "Sangat Layak" dan hasil validasi teman sejawat mendapatkan skor rata-rata sebesar 217,5 poin dari skor maksimum 250 poin dengan persentase $87,0 \%$ termasuk dalam kategori "Sangat Layak". Sehingga LKPD berbasis STEM yang dikembangkan dapat diujicobakan pada siswa dan digunakan dalam proses pembelajaran fisika.

Hasil respon peserta didik mencakup aspek layout/tampilan LKPD, bahasa/struktur LKPD, penyajian materi LKPD, dan manfaat LKPD. Hasil respon dari 3 orang peserta didik mendapatkan skor 
rata-rata 92 poin dari skor maksimum 110 poin dengan persentase $83,6 \%$ termasuk dalam kategori "Sangat Setuju".

Rata-rata penilaian produk ini adalah $86,1 \%$ dengan kategori "Sangat Layak" seperti yang ditunjukkan pada Gambar 5. Hal ini menunjukkan bahwa LKPD yang dikembangkan dapat digunakan dalam proses pembelajaran fisika. Siswa dapat belajar secara mandiri untuk mengembangkan kemampuan pemecahan masalah. Artinya pendekatan STEM memiliki dampak positif terhadap pembelajaran peserta didik (Kefalis \& Drigas, 2019; Psycharis, 2016; Sagala et al., 2019; Widya et al., 2019). Roberts \& Cantu (2012) yang menyatakan pembelajaran STEM dapat membantu peserta didik memecahkan masalah dan mengamplikasikannya pada berbagai situasi dihadapi pada kehidupan sehari-hari melalui sains, teknologi, teknik dan matematika.

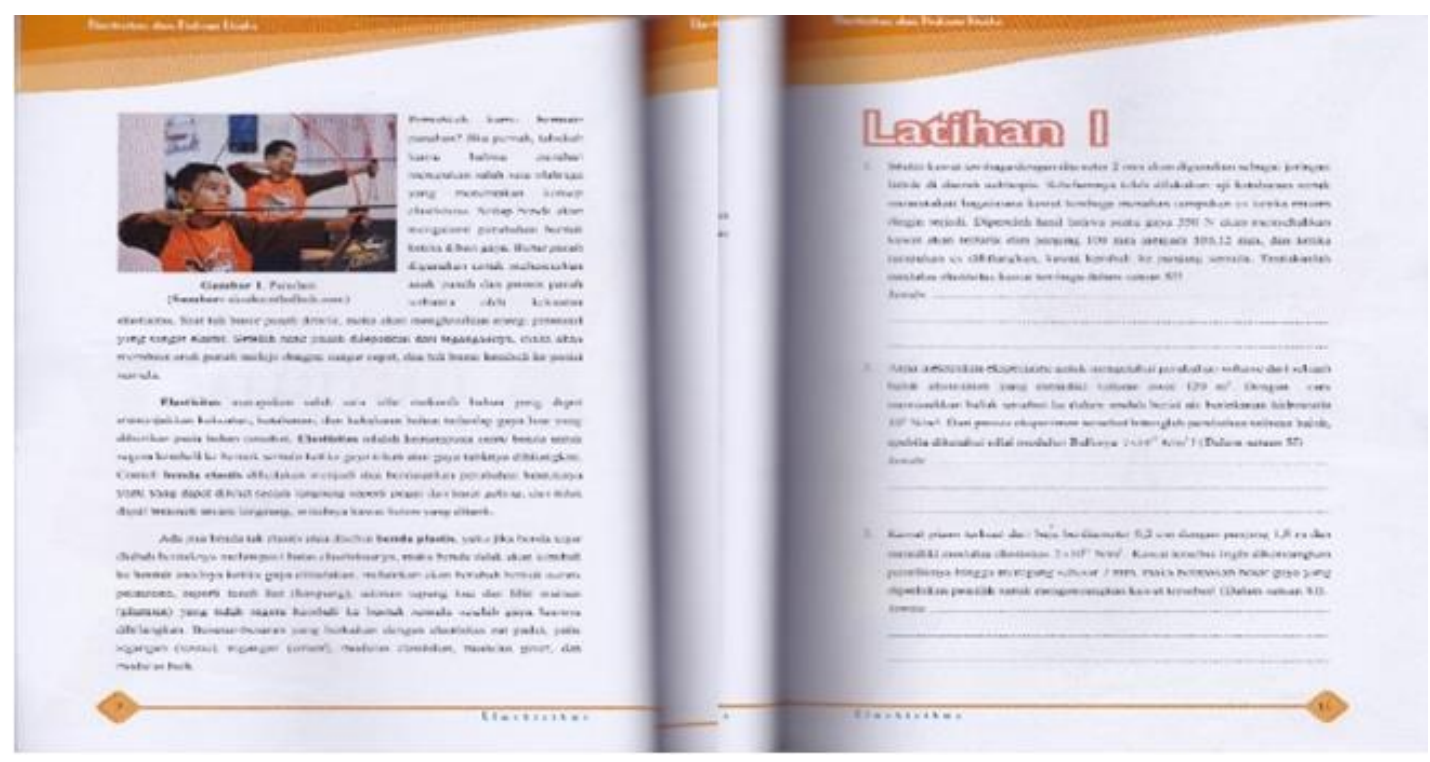

Gambar 3. Salah satu desain materi dan soal latihan
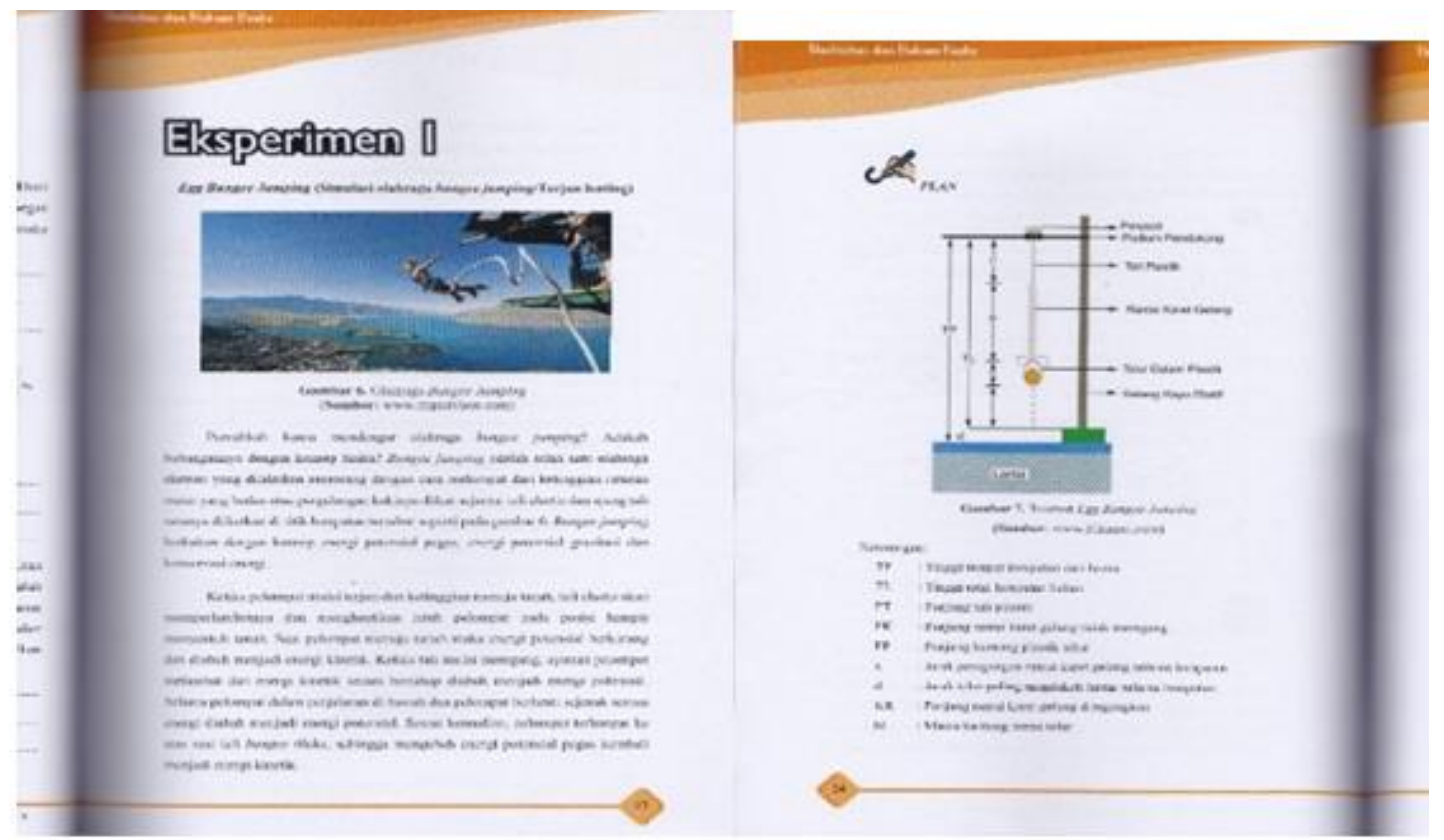

Gambar 4. Salah satu desain kegiatan eksperimen 


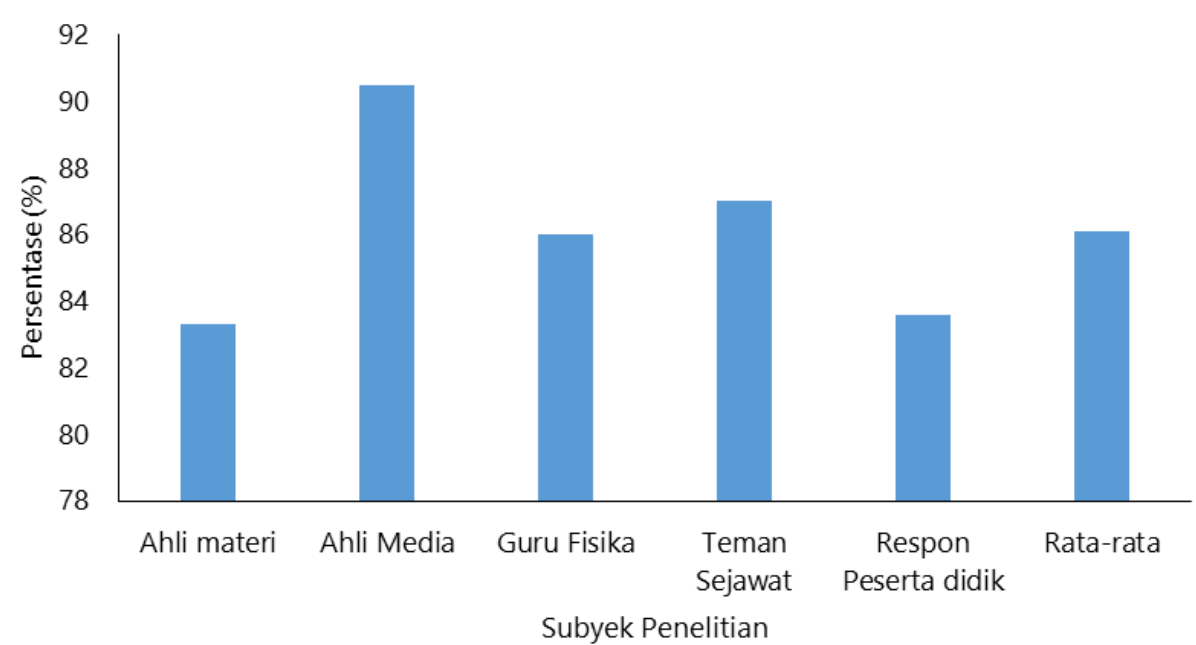

Gambar 5. Grafik hasil penilaian produk

\section{Simpulan}

Berdasarkan temuan, dapat disimpulkan bahwa telah dikembangkan Lembar Kerja Peserta Didik (LKPD) berbasis STEM pada pokok bahasan elastisitas dan hukum Hooke di Madrasah Mu'allimaat Muhammadiyah, Yogyakarta. Berdasarkan ahli materi, media, guru fisika dan teman sejawat, LKPD yang dikembangkan masuk dalam kategori sangat layak. Persentase masing-masing penilaian sebesar $83,3 \%$, $90,5 \%, 86 \%, 87 \%$. Sedangkan respon peserta didik sangat setuju dengan persentase sebesar $83,6 \%$. Rata-rata penilaian yang sebesar $86,1 \%$, kategori sangat layak. Oleh karena itu, LKPD berbasis STEM pada pokok bahasan elastisitas dan hukum Hooke sangat layak digunakan di Madrasah Mu'allimaat.

Kendala yang dihadapi pada penelitian ini adalah subjek uji coba yang tidak sesuai dengan rencana awal. Dikarenakan pandemi Covid-19, peneliti kesulitan mendapatkan izin dari sekolah untuk melakukan penelitian. Sehingga subjek uji coba tidak dapat dilakukan pada peserta didik dari MA Mu'allimaat Muhammadiyah Yogyakarta, tetapi dilakukan pada 3 responden dari SMAN 8 Yogyakarta yang merupakan kenalan peneliti.

\section{References}

Astuti, A. P., Aziz, A., Sumarti, S. S., \& Bharati, D. A. L. (2019). Preparing 21st century teachers: Implementation of 4C character's pre-service teacher through teaching practice. Journal of Physics: Conference Series, 1233, 012109.

Erdoğan, V. (2019). Integrating 4C skills of 21st century into 4 language skills in EFL classes. International Journal of Education and Research, 7(11), 113-124.

Giancoli, D. C. (2015). Physics Principles with Applications, Global Edition. England: Pearson Education Limited.

Irfana, S., \& Yulianti, D. (2019). Pengembangan lembar kerja peserta didik berbasis science, technology, engineering, and mathematics untuk meningkatkan kemampuan berpikir kreatif peserta didik. UPEJ Unnes Physics Education Journal, 8(1), 83-89.

Kaymakcı, S. (2012). A Review of studies on worksheets in Turkey. Education Review A, 1, 57-64.

Kefalis, C., \& Drigas, A. (2019). Web Based and Online Applications in STEM Education. International Journal of Engineering Pedagogy (IJEP), 9(4), 76-85. 
Lou, S.-J., Chou, Y.-C., Shih, R.-C., \& Chung, C.-C. (2017). A study of creativity in $\mathrm{CaC}_{2}$ steamship-derived STEM project-based learning. EURASIA Journal of Mathematics, Science and Technology Education, 13(6). 23872404.

Maloy, R. W., Verock, R. A., Edwards, S. A., \& Woolf, B. P. (2016). Transforming learning with new technology. New York: Pearson.

Psycharis, S. (2016). The impact of computational experiment and formative assessment in inquiry-based teaching and learning approach in STEM education. Journal of Science Education and Technology, 25(2), 316-326.

Puri, V. A. (2019). Pengembangan LKPD berbasis science, technology, engineering and mathematics (STEM) pada materi usaha dan energi di SMA Muhammadiyah 7. Eprints.uad.ac.id.

Redhana, I. W. (2019). Mengembangkan keterampilan abad Ke-21 dalam pembelajaran kimia. Jurnal Inovasi Pendidikan Kimia, 13(1), 2239 - 2253.

Roberts, A., \& Cantu, D. (2012). Applying STEM instructional strategies to design and technology curriculum. PATT 26 Conference: Technology Education in the 21st Century, 111-118.

Sagala, R., Umam, R., Thahir, A., Saregar, A., \& Wardani, I. (2019). The Effectiveness of STEM-Based on Gender Differences: The Impact of Physics Concept Understanding. European Journal of Educational Research, 8(3), 753-761.

Sugiyono. (2015). Metode penelitian kuantitatif, kualitatif dan R\&D. Bandung: Alfabeta.

Widya, Rifandi, R., \& Laila Rahmi, Y. (2019). STEM education to fulfil the 21 st century demand: a literature review. Journal of Physics: Conference Series, 1317, 012208.

Yu, T. X., \& Wan Mohammad, W. M. R. (2019). Integration of 21st century learning skills (4C elements) in interventions to improve english writing skill among $3 \mathrm{~K}$ class students. International Journal of Contemporary Education, 2(2), 100-121.

Zubaidah, S. (2019). STEAM (Science, Technology, Engineering, Arts, and Mathematics): Pembelajaran untuk memberdayakan keterampilan abad ke-21. STEAM Terintegrasi Kearifan Lokal dalam Menghadapi Era Revolusi Industri 4.0. Indramayu: FKIP Universitas Wiralodra Indramayu. 